\title{
A SIMPLIFIED CONTROL SCHEME FOR THREE-PHASE THREE-LEVEL (NPC) SERIES ACTIVE FILTER TO COMPENSATE ALL VOLTAGE PERTURBATIONS
}

\author{
Salim CHENNAI*, Mohamed Toufik BENCHOUIA** \\ *Electrical Engineering Department, Nuclear Research Center of Birine, Algeria, e-mail: chenaisalimov@yahoo.fr \\ Electrical Engineering Department, L.G.E.B, University of Biskra, Algeria
}

\begin{abstract}
This paper presents a simplified control scheme for three-phase three-level series active power filter to compensate all load voltage perturbations such us harmonic unbalances, sags and swells. The standard configuration of three-phase series active power filter uses the two-level three-phase voltage source inverter with hysteresis controller. This configuration presents some drawbacks and is limited to low power systems. Today three-level (NPC) inverter is one of the most successfully employed topology in various industrial applications. In this paper a new scheme to increase the capability of series Active Power Filter (APF) voltage controller based on three-level inverter using simplified Pulse Width Modulation (PWM), is proposed. The control strategy adopted use instantaneous reactive power theory, easy to implement and gives good performance for all load voltage perturbations. The numerical simulation results carried with MATLAB-Simulink and SimPowerSystem Toolbox show the effectiveness of the proposed control scheme.
\end{abstract}

Keywords: Logic voltage controller, Three-level (NPC) inverter, Series active power filter, Voltage perturbation compensation, Matlab-Simulink and SimPowerSystem Toolbox

\section{INTRODUCTION}

With proliferation of nonlinear loads, harmonic pollution is being considered as one of the major problems that degrade the power quality [1]. So far, shunt active power filters have been proposed as an interesting and high performance solution to improve the power quality, the shunt active power filter is used for reactive power and load current compensation by injecting equal but opposite harmonics current [2].

To protect sensible loads and improve the power quality in the distribution system, some solutions have been proposed by several authors. Among them the series active power filters have proven as an important and flexible alternative to compensate most important voltage perturbations [3].

The series active filter is especially used for compensation of voltage: unbalances, sags, swells and harmonics. The series active filter injects a voltage component in series with the supply voltage and can be regarded as a controlled voltage source [4]. The standard configuration is based on PWM-Voltage Source Inverter inserted in series between the load and the source voltage. Three single phase transformers are used to perform the series connection. This structure is limited to low power applications, for medium or high voltage three-level inverter is recommended.

The performance of any Series AF is based on three essentials design criteria: inverter topology, method used to determining the reference voltage compensation and lastly the controller capable to generate the inverter switching pulses. Today three-level inverter is one of the most widely employed multilevel topology and is applied in medium and high power applications [5]-[6]. The principally control techniques used to determining the compensation reference voltage are the instantaneous power theory [7] and the synchronous reference frame detection method [8]. The controller is the main part of any active power filter operation and has been a subject of many researches in recent years [9], pwm controller is a one of most commonly used controller with good performance compared to conventional hysteresis controller.

This paper presents a new pwm voltage controller for three-level neutral point clamped (NPC) series active filter for protecting sensible and critical voltage loads under all voltage perturbations.

Simulation results are presented in order to emphasize the good performance of the proposed series power filter topology. The systems performance is evaluated using Matlab-Simulink and SimPowerSystem Toolbox under different voltage perturbations in terms of source voltage Total Harmonic Distortion (THD) and robustness compensation under different source perturbations. The obtained results show the effectiveness of the proposed control scheme.

The organization of this paper begins with series active filter configuration based on three-level inverter, followed by control strategy adopted to calculate compensation voltages, before coming to the results simulation and discussion, and ended with conclusions.

\section{SERIES ACTIVE FILTER CONFIGURATION}

The circuit configuration of the series active filter is shown in figure 1 . The Series AF is inserted between the perturbed voltage source and a protected load. It is composed of three phase voltage source converter, $\mathrm{LfCf}$ filter to suppress switching ripples and series transformers which inject the compensating voltage to the line [10].

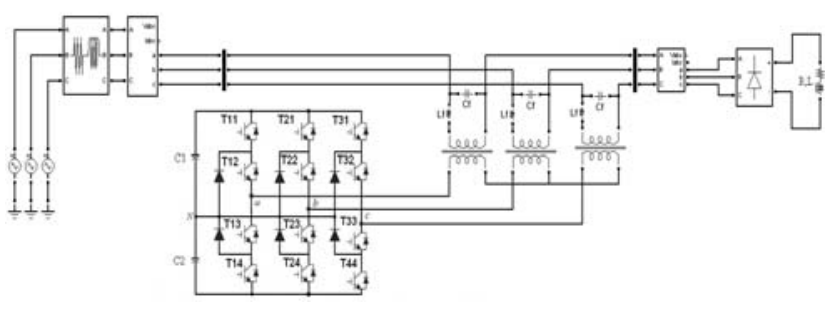

Fig. 1 Three-level (NPC) series active filter 


\section{THREE-LEVEL (NPC) INVERTER}

Multilevel inverters are being investigated and recently used for active filter topologies. Three-level inverters are becoming very popular today for most inverter applications, such as machine drives and power factor compensators. The advantages of these converters are reduction of the harmonic content generated by the active filter and decreasing the voltage or current ratings of the semiconductors. Figure 2 shows the three-level inverter based on the six main switches (T11, T21, T31, T14, T24, T 34) of the traditional two-level inverter, adding two auxiliary switches (T12, T13, T22, T23, T32, T33) and two neutral clamped diodes on each bridge arm respectively, the diodes are used to make the connection with the point of reference to obtain Midpoint voltages. For this structure, three kinds of output voltage level can obtain $\mathrm{Udc} / 2,0$ and $-\mathrm{Udc} / 2$ corresponding to three kinds of switching states $\mathrm{P}, 0, \mathrm{~N}$. As a result, there exist 27 kinds of switching output from the three-phase three-level inverter [11], [12].

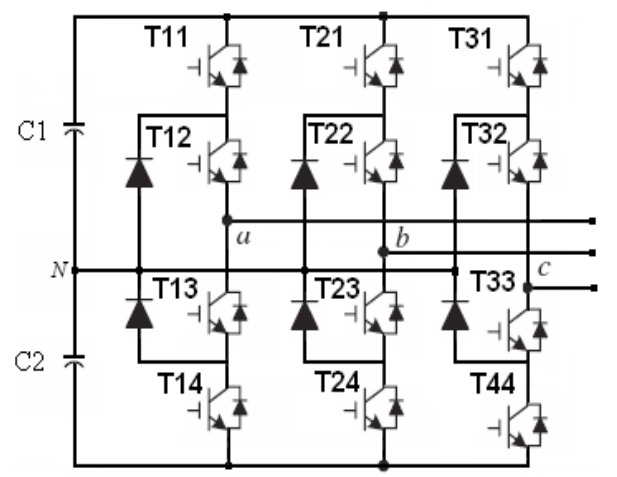

Fig. 2 Three-level NPC inverter

The switch connection function FKS indicates the opened or closed state of the switch TKS [12]:

$F_{K S}=\begin{array}{llll}1 & \text { If } & T_{k s} & \text { close } \\ 0 & \text { If } & T_{k s} & \text { open }\end{array}$

For a leg $\mathrm{K}$ of the three phases three-level NPC VSI, several complementary control laws are possible. The optimal control law of this inverter is:

$F_{K} 4=1-F_{K} 1$

$F K 3=1-F K 2$

Half leg connection function $F_{k m}^{b}$ is defined as:

$F_{K 4}^{b}=F K 1 F K 2$

$F_{K 0}^{b}=F K 3 F K 4$

With $\mathrm{m}=1$ for the lower half leg and $\mathrm{m}=0$ for the upper half leg.

As indicated in Table 1, each leg of the inverter can have three possible switching states, $\mathrm{P}, \mathrm{O}$, or $\mathrm{N}$. When the top two switches Tk1 and Tk2 are turned on, the switching state is $P$. When the medium switches Tk2 and Tk3 are turned on switching state is $\mathrm{O}$. When the lower switches $\mathrm{Tk} 3$ and Tk4 are turned on, the switching state is $\mathrm{N}$ [13].

Table 1 Switching states of three-level inverter

\begin{tabular}{|c|c|c|c|c|c|}
\hline $\begin{array}{r}\text { Switching } \\
\text { States }\end{array}$ & $\begin{array}{c}\text { Voltage } \\
\text { output }\end{array}$ & Tk1 & Tk2 & Tk3 & Tk4 \\
\hline $\mathrm{P}$ & $\mathrm{Ud} / 2$ & ON & ON & OFF & OFF \\
\hline 0 & 0 & OFF & ON & ON & OFF \\
\hline $\mathrm{N}$ & $-\mathrm{Ud} / 2$ & OFF & OFF & ON & ON \\
\hline
\end{tabular}

\section{REFERENCE VOLTAGE IDENTIFICATION}

The proposed series active filter adopted the power reactive theory to compensate all voltage perturbations. To extract the reference voltages a p-q theory described in [7], [8] is used. When the three-phase load instantaneous voltages Ulu, Ulv, Ulw and currents Ilu, Ilv, Ilw, are transformed into two-phase $(\alpha-\beta)$ coordinates, two phase voltages $\overrightarrow{u_{\alpha}}, \overrightarrow{u_{\beta}}$ and currents $\overrightarrow{i_{\alpha}}, \overrightarrow{i_{\beta}}$ are respectively given by:

$$
\begin{aligned}
& {\left[\begin{array}{l}
u_{\alpha} \\
u_{\beta}
\end{array}\right]=\sqrt{\frac{2}{3}}\left[\begin{array}{rrr}
1 & -\frac{1}{2} & -\frac{1}{2} \\
0 & \frac{\sqrt{3}}{2} & -\frac{\sqrt{3}}{2}
\end{array}\right]\left[\begin{array}{l}
U_{l u} \\
U_{l v} \\
U_{l w}
\end{array}\right]=C_{32}\left[\begin{array}{l}
U_{l u} \\
U_{l v} \\
U_{l w}
\end{array}\right]} \\
& {\left[\begin{array}{l}
i_{\alpha} \\
i_{\beta}
\end{array}\right]=\sqrt{\frac{2}{3}}\left[\begin{array}{ccc}
1 & -\frac{1}{2} & -\frac{1}{2} \\
0 & \frac{\sqrt{3}}{2} & -\frac{\sqrt{3}}{2}
\end{array}\right]\left[\begin{array}{l}
i_{l u} \\
i_{l v} \\
i_{l w}
\end{array}\right]=C_{32}\left[\begin{array}{l}
i_{l u} \\
i_{l v} \\
i_{l w}
\end{array}\right]}
\end{aligned}
$$

On the $(\alpha-\beta)$ plane, $\vec{u}$ can be considered to be composed of $\overrightarrow{u_{\alpha}}$ and $\overrightarrow{u_{\beta}}$ and $\vec{i}$ of $\overrightarrow{i_{\alpha}}$ and $\overrightarrow{i_{\beta}}$ :

$$
\begin{aligned}
& \vec{u}=\overrightarrow{u_{\alpha}}+\overrightarrow{u_{\beta}} \\
& \vec{i}=\overrightarrow{i_{\alpha}}+\overrightarrow{i_{\beta}}
\end{aligned}
$$

Assume that $u_{p}$ is the projection of $\vec{u}$ in the direction of $\vec{i}$ and $u_{q}$ the projection of $\vec{u}$ in the vertical direction of $\vec{i} ; u_{p}$ and $u_{q}$ can be represented by:

$\left[\begin{array}{l}u_{p} \\ u_{q}\end{array}\right]=\left[\begin{array}{cc}\sin \omega t & -\cos \omega t \\ -\cos \omega t & -\sin \omega t\end{array}\right]\left(\sqrt{\frac{2}{3}}\left[\begin{array}{ccc}1 & -\frac{1}{2} & -\frac{1}{2} \\ 0 & \frac{\sqrt{3}}{2} & -\frac{\sqrt{3}}{2}\end{array}\right]\right)\left[\begin{array}{c}U_{l u} \\ U_{l v} \\ U_{l w}\end{array}\right]$

$\left[\begin{array}{l}u_{p} \\ u_{q}\end{array}\right]=C_{p q} C_{32}\left[\begin{array}{c}U_{l u} \\ U_{l v} \\ U_{l w}\end{array}\right]$

Where $C_{p q}$ is the $\mathrm{pq}$ transformation matrix, which executes the calculation to convert the two-phase voltages $u_{\alpha}$ and $u_{\beta}$ into $u_{p}$ and $u_{q}$. 
When Ulu, Ulv and Ulw are the three-phase voltage source, the respective components $\overline{u p}$ and $\overline{u q}$ in $u_{p}$ and $u_{q}$ are corresponding to the positive sequence fundamental active and reactive components in three-phase voltages.

The fundamental components Uluf, Ulvf and Ulwf in load voltages can be obtained by an inverse transformation of (7):

$$
\begin{aligned}
& {\left[\begin{array}{l}
U_{l u f} \\
U_{l v f} \\
U_{l w f}
\end{array}\right]=\left(\sqrt{\left.\frac{2}{3}\left[\begin{array}{ccc}
1 & -\frac{1}{2} & -\frac{1}{2} \\
0 & \frac{\sqrt{3}}{2} & -\frac{\sqrt{3}}{2}
\end{array}\right]\right)\left[\begin{array}{cc}
\sin \omega t & -\cos \omega t \\
-\cos \omega t & -\sin \omega t
\end{array}\right]\left[\frac{\overline{u_{p}}}{u_{q}}\right.}\right]} \\
& {\left[\begin{array}{l}
U_{l u f} \\
U_{l v f} \\
U_{l w f}
\end{array}\right]=C_{23} C_{p q}-1\left[\frac{\overline{u_{p}}}{u_{q}}\right]}
\end{aligned}
$$

Where $C_{p q}^{-1}$ is the inverse matrix of $C_{p q}$, which executes the calculation to convert $\overline{u_{p}}$ and $\overline{u_{q}}$ back into $(\alpha-\beta)$ coordinates. Hence the voltage compensation can be calculated out as:

$$
\left[\begin{array}{l}
U_{l u c} \\
U_{l v c} \\
U_{l w c}
\end{array}\right]=\left[\begin{array}{l}
U_{l u} \\
U_{l v} \\
U_{l w}
\end{array}\right]-\left[\begin{array}{l}
U_{l u f} \\
U_{l v f} \\
U_{l w f}
\end{array}\right]
$$

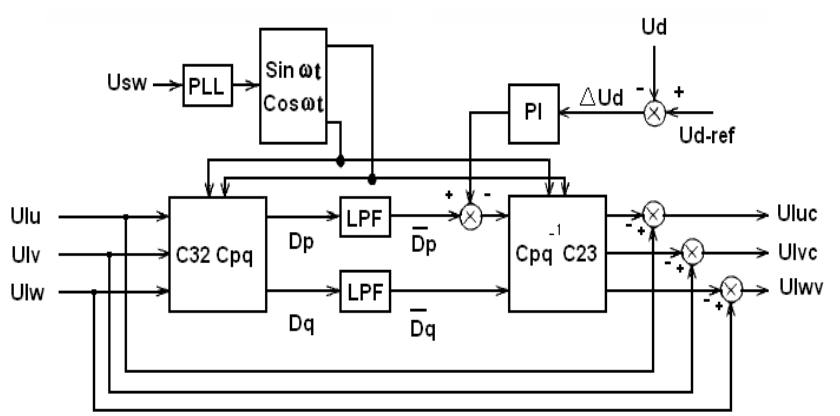

Fig. 3 Reference compensation voltage calculation

\section{SERIES ACTIVE FILTER LOGIC CONTROL}

The PWM logic controller for three-level (NPC) inverter proposed to replace conventional hysteresis controller is shown in figure 4 . The difference between the injected voltage and the reference voltage determines the reference voltage (e), this output voltage is compared with two carrying triangular identical waves shifted one from other by a half period of chopping and generate switching pulses[14].

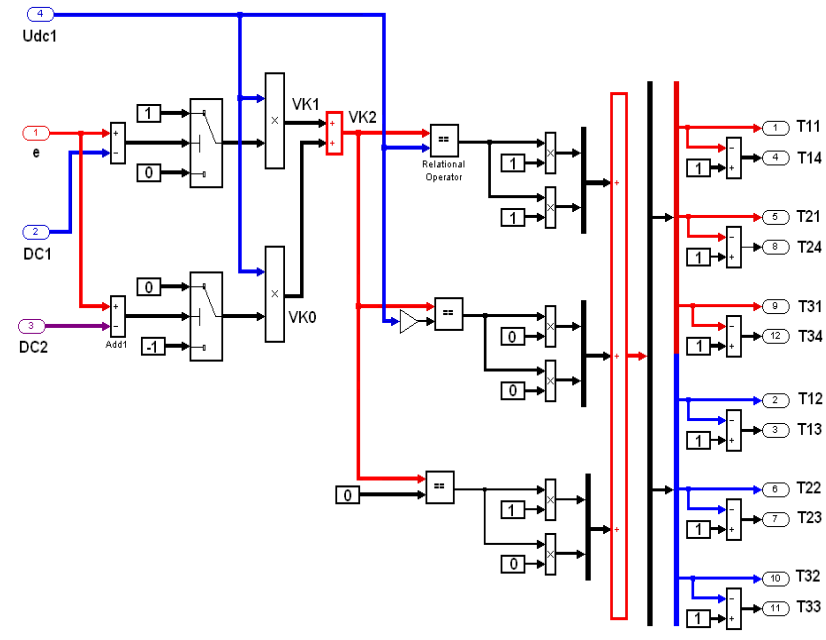

Fig. 4 PWM logic control

The control of inverter is summarized in the two following stages:

Determination of the intermediate signals $\mathrm{Vi1}$ and $\mathrm{Vi2}$ :

- If error Ec $\geq$ carrying 1 Then $\mathrm{Vi}_{\mathrm{i}}=1$,

- If error $\mathrm{E}_{\mathrm{c}}<$ carrying 1 Then $\mathrm{V}_{\mathrm{i} 1}=0$,

- If error $\mathrm{Ec}_{\mathrm{c}} \geq$ carrying 2 Then $\mathrm{Vi} 2=0$,

- If error Ec < carrying 2 Then $\mathrm{V} i 2=-1$.

Determination of control signals of the switches $\mathrm{Tij}$ $(i=1,2,3 ; j=1,2,3,4)$ :

- If $(\mathrm{Vi} 1+\mathrm{Vi} 2)=1$ Then $\mathrm{Ti} 1=1, \mathrm{Ti} 2=1, \mathrm{Ti} 3=0, \mathrm{Ti} 4=0$,

- If $\left(\mathrm{V}_{1} 1+\mathrm{Vi} 2\right)=0$ Then $\mathrm{Ti} 1=0, \mathrm{Ti} 2=1, \mathrm{Ti} 3=1, \mathrm{Ti} 4=0$,

- If $(\mathrm{Vi} 1+\mathrm{Vi} 2)=-1$ Then $\mathrm{Ti} 1=0, \mathrm{Ti} 2=0, \mathrm{Ti} 3=1, \mathrm{Ti} 4=1$.

\section{SIMULATION RESULTS AND DISSCUSSION}

The Matlab-Simulink simulation block diagram of the proposed three-level series active filter based on pwm voltage controller is shown in figure 5 . The model parameters used for simulation are: Voltage source $\mathrm{V}_{\mathrm{s}}=220 \mathrm{~V}$, Frequency $\mathrm{Fs}_{\mathrm{s}}=50 \mathrm{~Hz}$, Resistor $\mathrm{Rs}_{\mathrm{s}}=0.1 \mathrm{~m} \Omega$, Inductance $\mathrm{Ls}=0.0002 \mathrm{mH}$, Resistor $\mathrm{R} 1=48.6 \Omega$, Inductance $\mathrm{Ll}=40 \mathrm{mH}$, Capacitance $\quad \mathrm{C}_{1}=\mathrm{C}_{2}=300 \mu \mathrm{F}$, Resistor $\mathrm{Rc}_{\mathrm{c}}=0.27 \mathrm{~m} \Omega$, Inductance $\mathrm{Lc}_{\mathrm{c}}=0.8 \mathrm{mH}$.

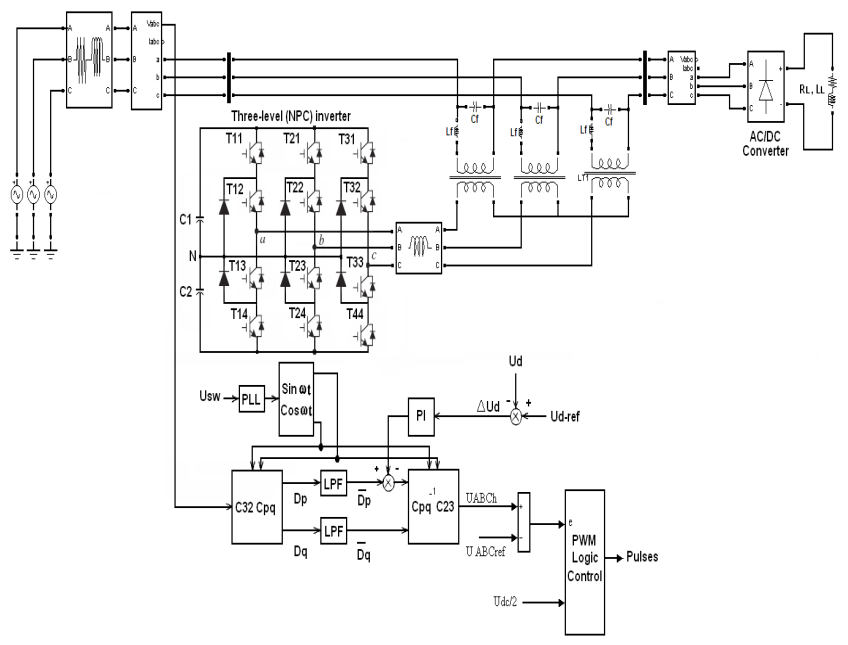

Fig. 5 Three-level series active filter using pwm voltage controller based on $\mathrm{p}-\mathrm{q}$ theory 
The proposed series active power filter is simulated under MATLAB-Simulink and SimPower System environment to estimate its' performance. It is tested for several different operating conditions such as steady-state, transient condition for voltage sag, swell, unbalance and under balanced distorted utility voltages, intending to validate the Series APF system performance. The simulation results obtained for all voltage perturbations are shown in figures 6 to 12 and discussed in the following subsections.

\subsection{Voltage harmonics compensation}

When the three-phase voltages are balanced-distorted, the mains voltages contain the fundamental component and harmonic components. The expression of the balanced-distorted voltages source used is expressed bellow:

$v_{s a}=311 \sin (\omega t)+141 \sin (2 \omega t)+35 \sin (4 \omega t)+14 \sin (5 \omega t)$

$v_{s b}=311 \sin \left(\omega t+\frac{4 \pi}{3}\right)+141 \sin \left(2 \omega t+\frac{2 \pi}{3}\right)$

$+35 \sin \left(4 \omega t+\frac{4 \pi}{3}\right)+14 \sin \left(5 \omega t+\frac{2 \pi}{3}\right)$

$v_{s c}=311 \sin \left(\omega t+\frac{2 \pi}{3}\right)+141 \sin \left(2 \omega t+\frac{4 \pi}{3}\right)+35 \sin \left(4 \omega t+\frac{2 \pi}{3}\right)$

$+14 \sin \left(5 \omega t+\frac{4 \pi}{3}\right)$

At time $\mathrm{t}_{1}=0.1 \mathrm{~s}$ to $\mathrm{t} 2=0.2 \mathrm{~s}$, harmonic voltage perturbation is introduced voluntarily in the utility. The series APF is put into the operation; it starts immediately the process of compensation. The load voltage before series active filter operation, three-phase fundamental voltages, injected voltages by series APF and the threephase compensated voltages delivered to critical load are shown in figure 7. After compensation the THD of the load voltage is reduced from $46.93 \%$ to $3.52 \%$ in conformity with IEEE-519 standard Norms.

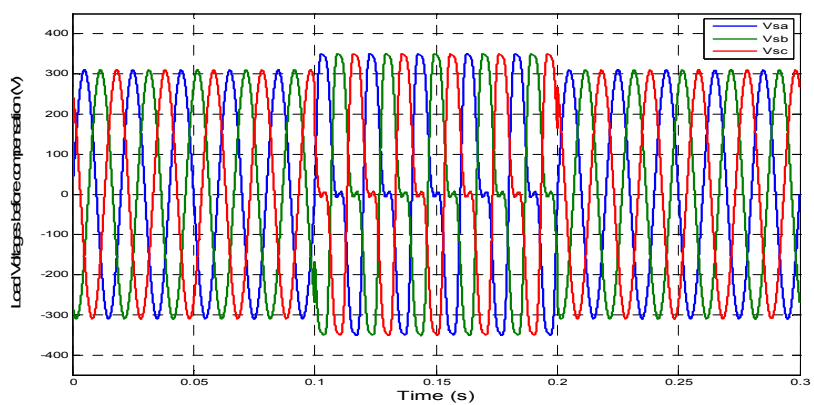

(a) Load voltages before compensation

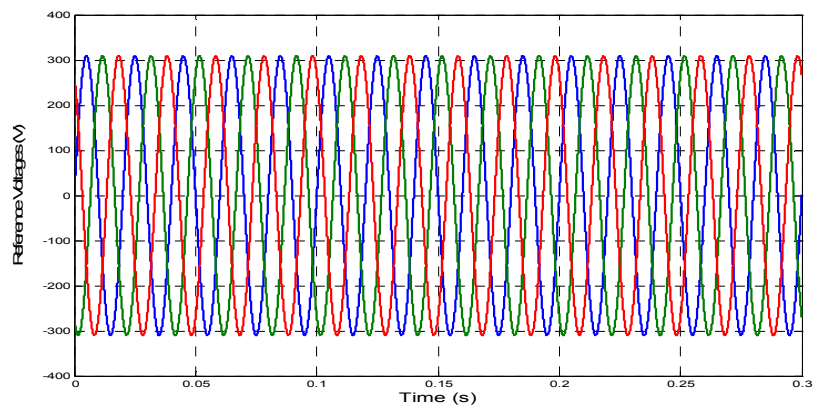

(b) Reference voltages

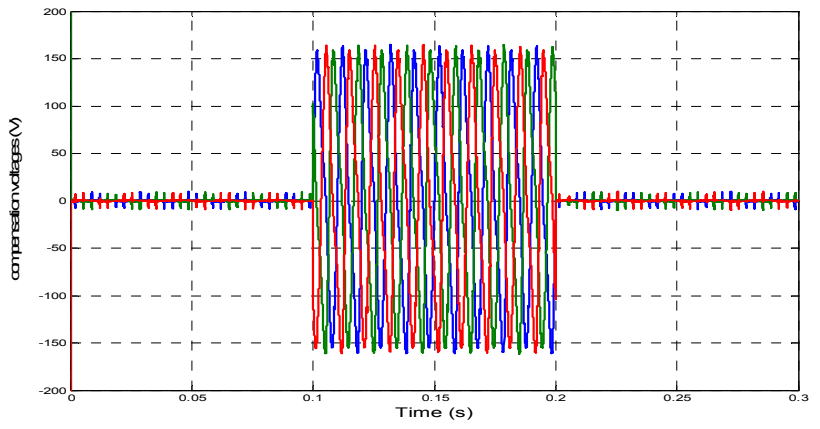

(c) Compensation voltages

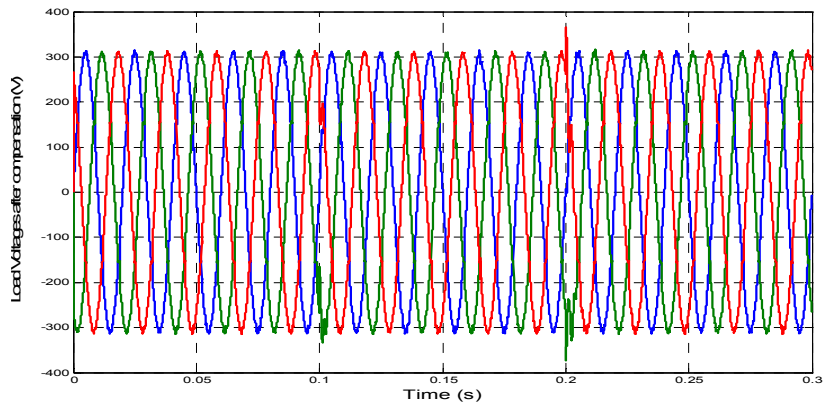

(d) Load voltages after compensation

Fig. 6 Simulation results with harmonics voltage compensation

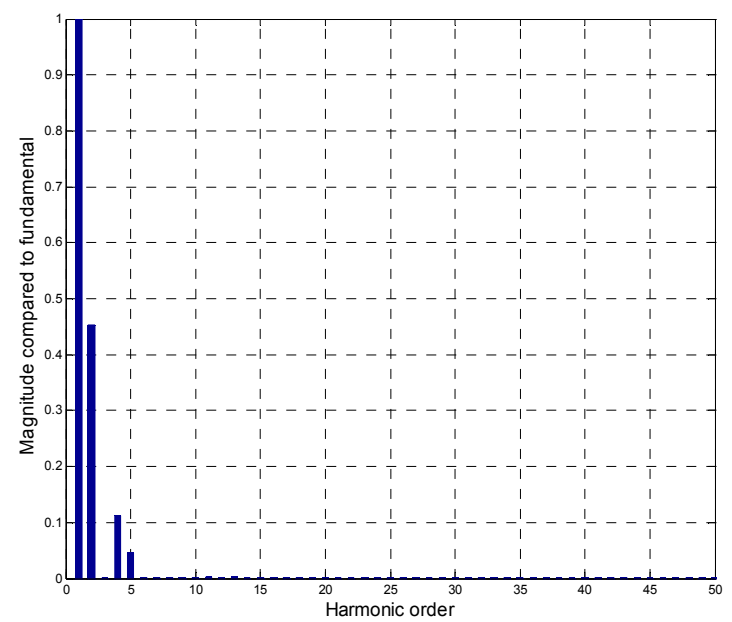

Fig. 7 Load voltage harmonic spectrum without Series AF (Fundamental $(50 \mathrm{~Hz})=310.1, \mathrm{THD}=46.93 \%$ )

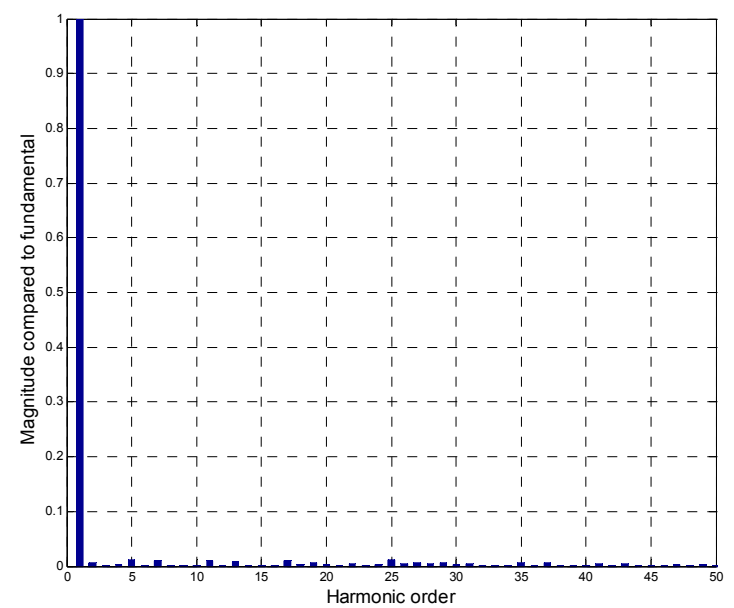

Fig. 8 Load voltage harmonic spectrum with Series AF (Fundamental $(50 \mathrm{~Hz})=308.2, \mathrm{THD}=3.52 \%$ ) 


\subsection{Voltage unbalances compensation}

In this case, the three phase voltages sources are unbalanced, but do not contain harmonic components, their expressions are given in (11):

$v_{s a}=311 \sin (\omega t)+31 \sin (\omega t)$

$v_{s b}=311 \sin \left(\omega t+\frac{4 \pi}{3}\right)+31 \sin \left(\omega t+\frac{2 \pi}{3}\right)$

$v_{s c}=311 \sin \left(\omega t+\frac{2 \pi}{3}\right)+31 \sin \left(\omega t+\frac{4 \pi}{3}\right)$

Figure 9 shows the three-phase voltage load, threephase fundamental voltages, three-phase voltage compensation and the three-phase compensated load voltage with unbalance voltage perturbation introduced voluntary between $\mathrm{t}_{1}=0.1 \mathrm{~s}$ and $\mathrm{t} 2=0.2 \mathrm{~s}$.

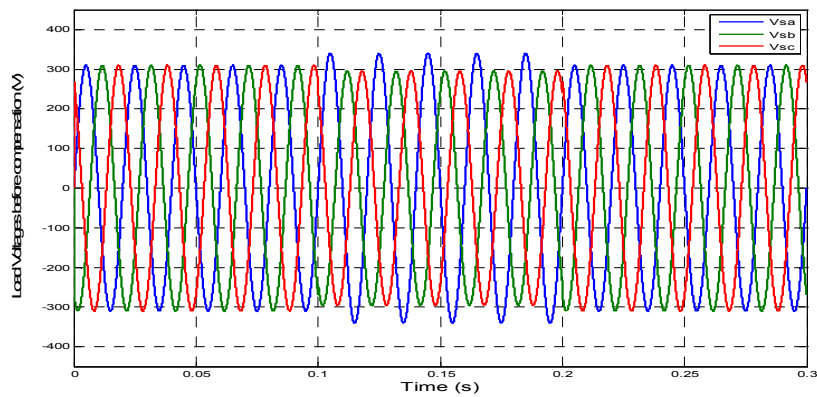

(a) Load voltages before compensation

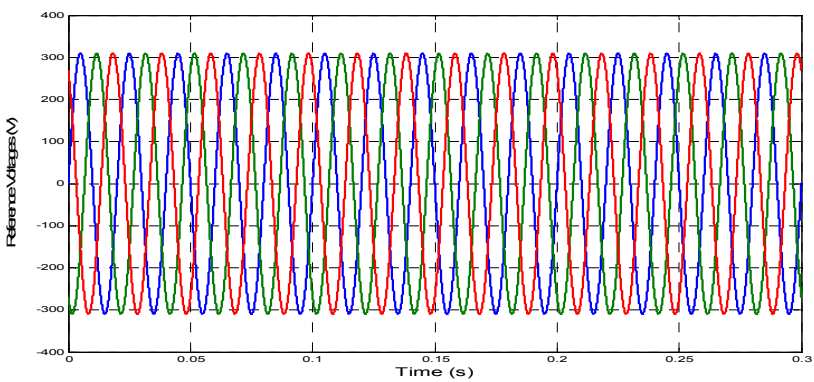

(b) Reference voltages

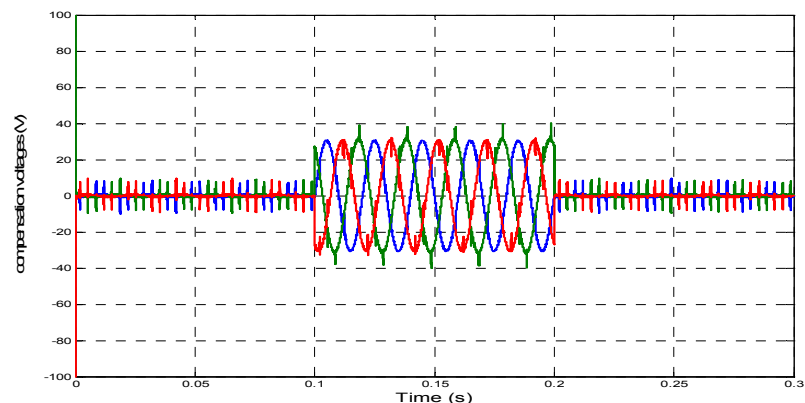

(c) Compensation voltages

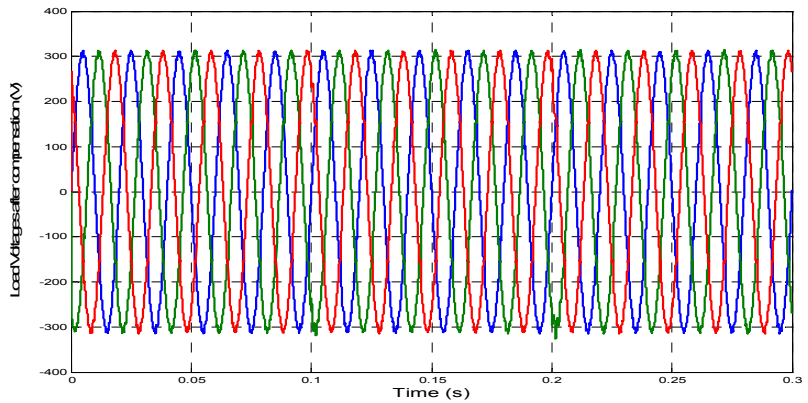

(d) Load voltages after compensation

Fig. 9 Simulation results with unbalances voltage compensation

\subsection{Voltage sags compensation}

To study the performance of series active filter during voltage sag conditions, we suppose that the load voltage is sinusoidal and the sag $(35 \%)$ is introduced voluntary between instants $\mathrm{t} 1=0.1 \mathrm{~s}$ and $\mathrm{t} 2=0.2 \mathrm{~s}$. The expression of the sag voltage is given by equation (12):

$$
\begin{aligned}
& v_{s a}=200 \sin (\omega t) \\
& v_{s b}=200 \sin \left(\omega t+\frac{4 \pi}{3}\right)
\end{aligned}
$$

$v_{s c}=200 \sin \left(\omega t+\frac{2 \pi}{3}\right)$

The series APF is put into operation instantly to compensate this perturbation. After instant $\mathrm{t} 2=0.2 \mathrm{~s}$, the system is again at normal working condition. The load

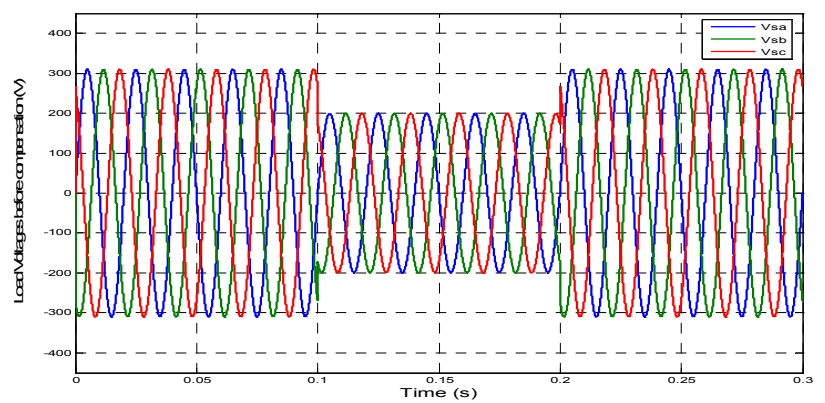

(a) Load voltages before compensation

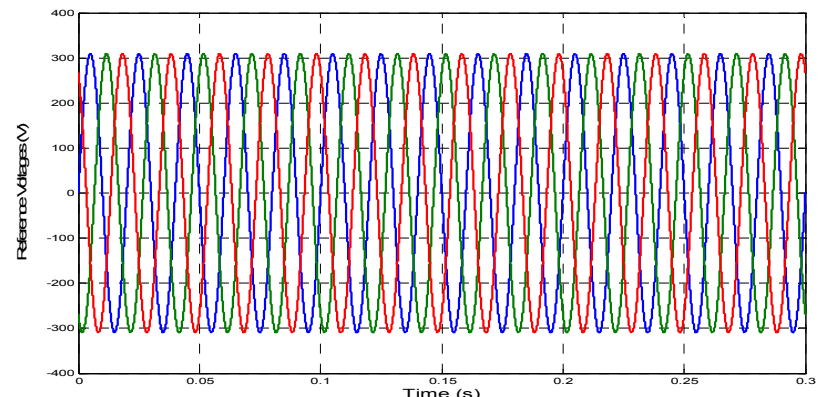

(b) Reference voltages

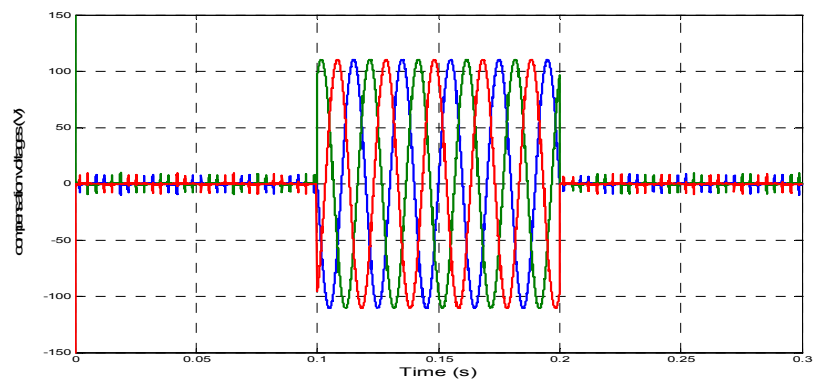

(c) Compensation voltages

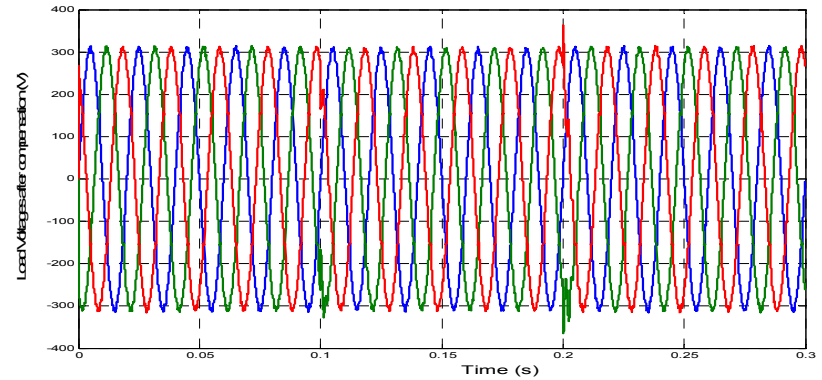

(d) Load voltages after compensation

Fig. 10 Simulation results with sags voltage compensation 
voltages, three-phase fundamental voltages, compensating voltages and the load voltages after compensation obtained by simulation are shown in figure 10 .

\subsection{Voltage swells compensation}

A swell (35\%) is now introduced on the system during the time $\mathrm{t} 1=0.1 \mathrm{sec}$ to $\mathrm{t} 2=0.2 \mathrm{sec}$. Under this condition the series APF injects an out of phase compensating voltage $(\approx 30 \%)$ in the line through series transformers, equal to the difference between the reference load voltage and voltage without compensation. As shown in figure 11 the load voltage profile before compensation, three-phase fundamental voltages, the compensating voltages in and the load voltages after compensation using the proposed series active filter. The expression of the swell voltage is given by equation (13):

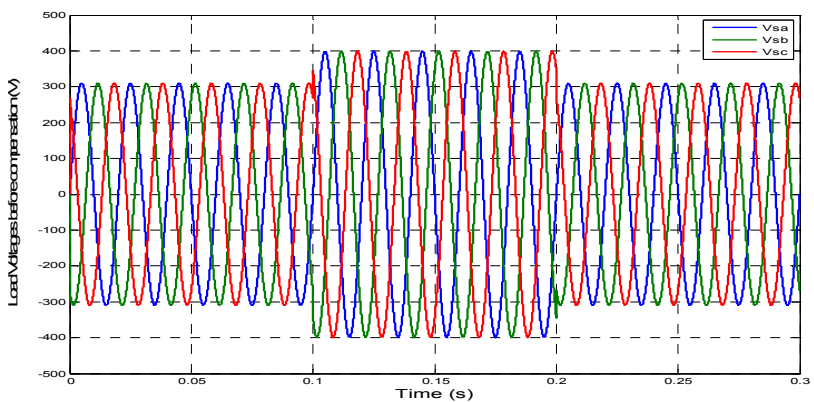

(a) Load voltages before compensation

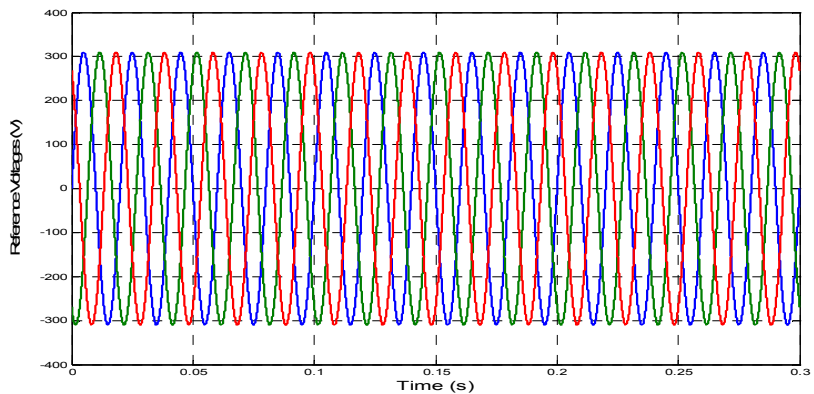

(b) Reference voltages

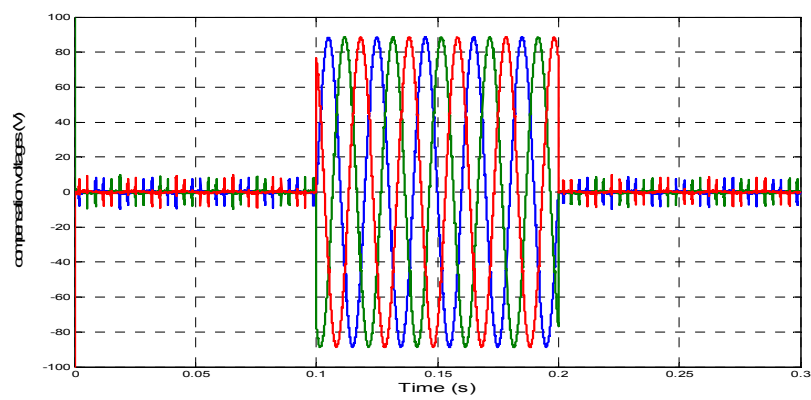

(c) Compensation voltages

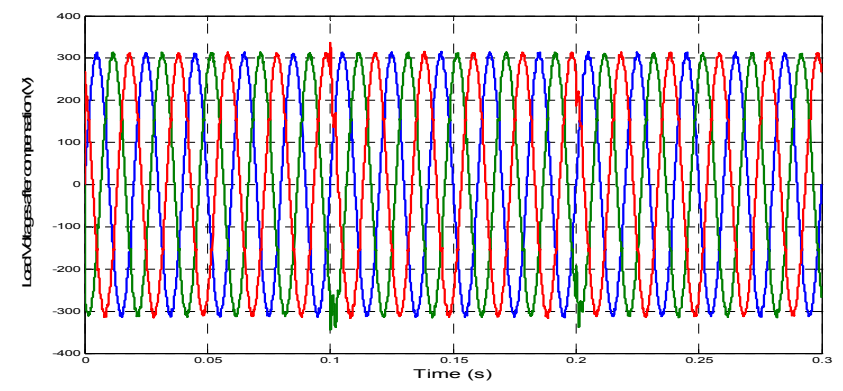

(d) Load voltages after compensation

Fig. 11 Simulation results with swells voltage compensation ISSN 1335-8243 (print) @ 2011 FEI TUKE www.aei.tuke.sk $v_{s a}=400 \sin (\omega t)$
$v_{s b}=400 \sin \left(\omega t+\frac{4 \pi}{3}\right)$
$v_{s c}=400 \sin \left(\omega t+\frac{2 \pi}{3}\right)$

\subsection{All voltage perturbation compensation}

The performance of the proposed Series active power filter system is also tested under all voltage perturbations simultaneously. The simulation results are shown in figure 13. The voltage swell is introduced voluntarily in the utility voltage $(35 \%)$ between $\mathrm{t} 1=0.1 \mathrm{~s}$ and $\mathrm{t} 2=0.16 \mathrm{~s}$. And after that, a voltage sags $(30 \%)$ is introduced between $\mathrm{t}_{2}=0.16 \mathrm{~s}$ and $\mathrm{t} 3=0.22 \mathrm{~s}$. The voltage harmonics is introduced between $\mathrm{t} 3=0.22 \mathrm{~s}$ and $\mathrm{t} 4=0.28 \mathrm{~s}$. The voltage

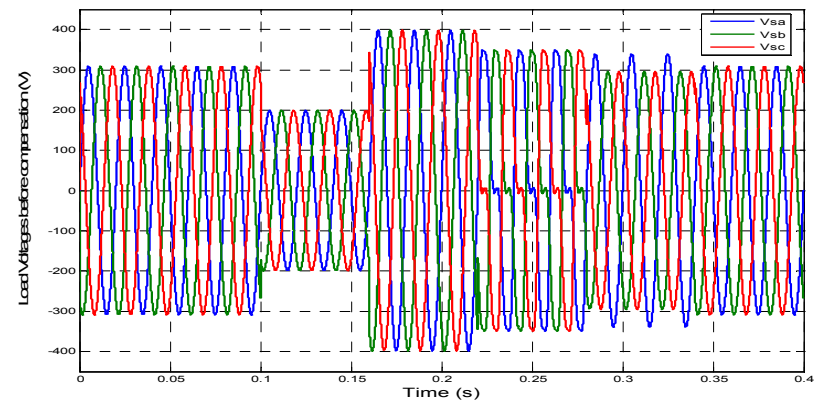

(a) Load voltages before compensation

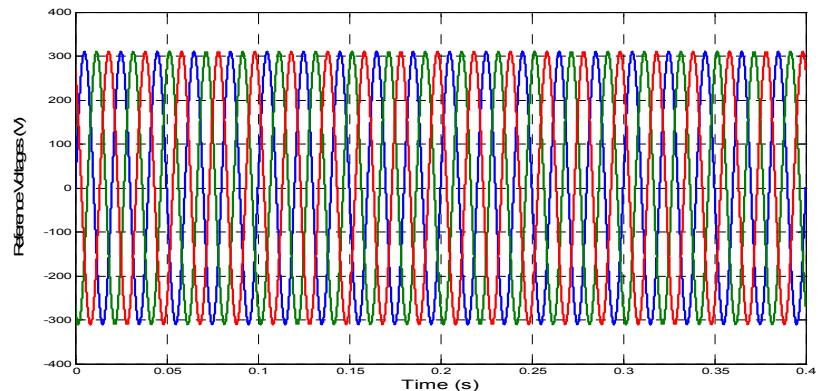

(b) Reference voltages

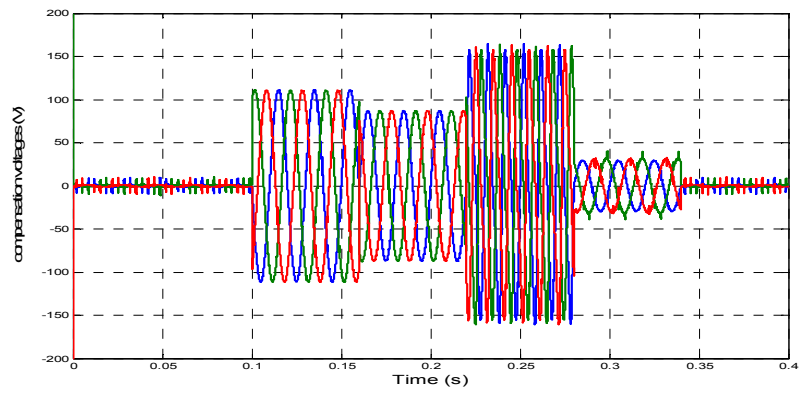

(c) Compensation voltages

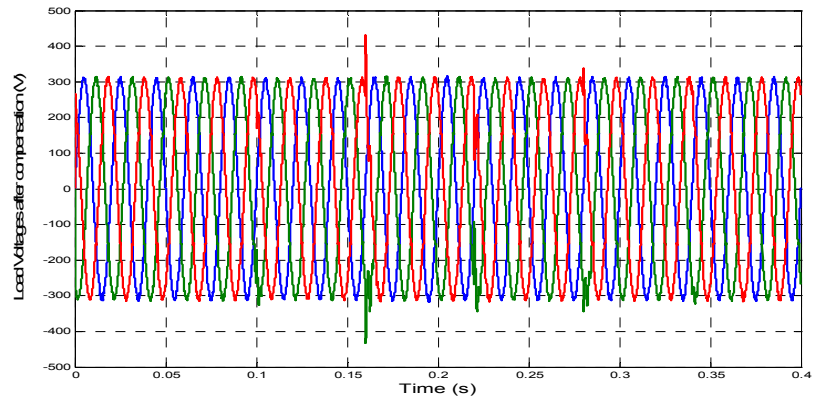

(d) Load voltages after compensation

Fig. 12 Simulation results with all voltage compensation 
unbalances is introduced between $\mathrm{t} 4=0.28 \mathrm{~s}$ and $\mathrm{t} 5=0.34 \mathrm{~s}$. After $t 5=0.34 \mathrm{~s}$ the system is again at normal working condition. The load voltages, three-phase fundamental voltages, compensating voltages and the load voltages after compensation obtained by simulation are shown in figure 12. It is illustrate that the proposed system does not show any significant effect of distortion present in the utility voltages on its compensation capability and the load voltage under all voltage perturbations is maintained constant and sinusoidal.

The performance of the proposed series AF system is tested under all voltage perturbations separately and simultaneously: harmonics, swells, sags and unbalances. Figures 7 and 8 show respectively the harmonic spectrum of the voltage delivered to sensible loads before and after application of the series active filter. It is observed that the load voltage harmonics is widely reduced from $46.93 \%$ to $3.52 \%$ in conformity with standard Norms. In cases of voltage swell $(35 \%)$, voltage sag $(30 \%)$ and unbalances introduced voluntarily in the supply voltage between $\mathrm{t} 1=0.1 \mathrm{~s}$ and $\mathrm{t} 2=0.2 \mathrm{~s}$, the load voltage is instantly compensated. The effectiveness of the proposed series active filter has been demonstrated in maintaining the three-phase load voltages balanced and sinusoidal, moreover the proposed system does not show any significant effect of perturbation type present in the utility voltages on its compensation capability and the load voltage under all voltage perturbations is maintained constant and sinusoidal.

\section{CONCLUSIONS}

To enhance the power quality and improve the voltage delivered to sensible and critical loads, a new series active power filter configuration using pwm voltage controller based on three-level (NPC) inverter topology has been proposed in this paper. The voltage perturbations studied in this paper concern voltage: harmonics, sags, swells and unbalances, all these perturbations are successfully compensated using the proposed system. The load voltage harmonic levels are maintained below IEEE-519 standard Norms when the source voltage is distorted, the THD of the load voltage is significantly reduced from $46.93 \%$ to $3.52 \%$. The simulation results show that the new system is efficacies and compensates all type of voltage perturbations. However, the current source is highly distorted and rich on harmonics. To eliminate this drawback, the future research work will be focused on current source compensation using hybrid series active filter configuration or Unified Power Quality Conditioner system.

\section{REFERENCES}

[1] HONGHAO ZHONG - PINGPING CHEN ZHENGYU LU - ZHAOMING QIAN: Novel Control Scheme Based on Per-phase Reference Current Calculation for Hybrid Series Active Power Filter with Fundamental Current Bypass Channel in Unbalanced Conditions, IEEE, 35th Annual Power Electronics Specialists Conference, pp. 999-1002, 2004.
[2] AB. HAMADI - S. RAHMANI K. - AL-HADDAD: Series Active Filter to mitigate power quality for medium size industrial loads (multi-pulses transformer and modern AC drive, IEEE, ISIE, pp. 1510-1515, 2006.

[3] AB. HAMADI - S. RAHMANI K. - AL-HADDAD: A new hybrid series Active Filter configuration to compensate voltage sag, swell, voltage and current harmonics and reactive power, IEEE, International Symposium on Industrial Electronics, pp. 286-291, 2009.

[4] F. Z. PENG - H. AKAGI - A. NABAE: A new approach to harmonic compensation in power systems a combined system of shunt passive and series active filters, IEEE Trans. Ind. Applicat., vol. 26, $n^{\circ}$ 6, pp. 983-990, 1990.

[5] O. VODYAKHO - D. HACKSTEIN -A. STEIMEL - T. KIM: Novel direct current-space vector control for shunt active power filters based on three-level inverters, IEEE, pp. 1868-1873, 2008.

[6] O. VODYAKHO - T. KIM - S. KWAK: Comparison of the space vector current controls for shunt active power filters, IEEE, pp. 612-617, 2008.

[7] REYES H. HERRERA - PATRICIO SALEMERON - HOYOSUNG KIM: Instantaneous Reactive Power Theory Applied to Active Power Filter Compensation: Different Approaches, Assessment, and Experimental Results," IEEE, Trans. on Industrial Electronics, pp. 184-196, 2008.

[8] S.BHATTACHRYA - D. DIVAN: Synchronous frame based controller implementation for a hybrid series active filter systems, IEEE, pp. 2531-2537, 1995.

[9] GUIYING LIU - SHIPING SU - PENG PENG: "Intelligent Control and Application of All-function Active Power Filter," IEEE, International Conference on Intelligent Computation Technology and Automation, pp. 1078-1081, 2008.

[10] FATIHA MEKRI - MOHAMED MACHMOUM NADIA AIT AHMED -BENYOUNES MAZARI: A comparative studies of voltage controllers of series active power filter, Elsevier, Electric power systems research, Article in press, pp. 1-12, 2009.

[11] A. MUNDUATE - E. FIGURERES - G. GARCERA: Robust model-following control of a three-level neutral point clamped shunt active filter in the medium voltage range, Elsevier, Electrical Power and Energy Systems 31, pp. 577-588, 1998.

[12] YUN WAN - JIANGUO JIANG.: The study of FPGA-based three-level SVM NPC inverter", IEEE, pp.1470-1474, 2009.

[13] T. ABDELKRIM - K. BEAMRANE - E. M. BERKOUK - T. BENSLIMANE: Neutral Point potential balancing algorithm for sliding mode controlled three-level power filter, Electrical Engineering Journal, EEJ, 2010. 
[14] CHENNAI S. - BENCHOUIA, M. T. -GOLÉA, A. - ZOUZOU, S. E.: Fuzzy logic current controller for shunt active filter to compensate harmonic currents based on ANN dc voltage regulator, International Conference on Electrical Engineering, Electronics and Automatics, ICEEA'10, 2010.

Received June 12, 2011, accepted November 18, 2011

\section{BIOGRAPHIES}

Chennai Salim was born in Biskra, Algeria, on February 03, 1969. He obtained his engineering degree in Electrotechnics from Biskra University in 1992. He was recruited in 1993 as senior engineer in power electronics in the Nuclear Research Center of Birine, Algeria. Since
2000, he has been working as researcher in the Electrical Engineering Department. He obtained his M.Sc degree in electrical engineering in 2009 from Medea University. He is currently working towards his $\mathrm{PhD}$ degree in Electrical Engineering from Biskra University, Algeria. His research interests are electrical drives, power electronics, energy quality, power systems, and intelligent control.

Benchouia Mohamed Toufik $\mathrm{He}$ received his engineering degree in Electrotechnics and M.Sc degree in electrical engineering from Biskra University in 1991 and 1998, respectively. He obtained his Ph.D. in electrical engineering from Biskra University in 2006. Since 2001, he has held teaching and research positions in the Electrical Engineering Department of Biskra University, Algeria. His research interests include electrical drives, power electronics, energy quality and power systems. 